Two cases also of failure of vision occur to me from excessive use of tobacco. One was a clergyman who had been presented with a very fine meerschaum pipe which he had been smoking almost incessantly in orier to color it. With failure of vision he was troubled also with palpitation of the heart with syncope, which greatly alarmed him. Upon following my advice to quit his smoking his vision returned. The other case was a tobacco manufacturer, also of middle age. $\mathrm{He}$ was a great smoker of cigars of the best quality, using as many as twenty or thirty daily. His failure of sight led him to consult me. I advised him to give up his cigars and all use of tobacco. His vision at once improved and became normal.

Dr. MYLES STANDISH: Several years ago I reported in detail a case of tobacco and alcohol amblyopia which was followed, as the patient persisted in his habits, by an alcoholic multiple neuritis. At that time I suggested that in all probability the amblyopia was also a peripheral neuritis. Since that time it has been my fortune to see three more cases of amblyopia ex abusu, in which the excess was not subsequently moderated, and which about three months later was followed by an alcoholic peripheral multiple neuritis. In two of these cases there was present a very noticeable whitening of the greater portion of the temporal half of one nerve at least. At the time I reported the first case I looked up the literature of alcoholic multiple neuritis and found that in the report of a number of cases reported by Dr. — in which the eyes were examined, the sight was found diminished, and the note was also made that in several cases the temporal halves of nerves were remarkably white. It is my opinion that cases of toxic amblyopia, whether due to tobacco, alcohol or lead, are undoubtedly a part of a peripheral multiple neuritis which, unless the toxic agent is stopped, may appear in other nerves.

DR. E. J. GARDINER reported a typical case of tobacco amblyopia occurring in a clergyman, a total abstainer from liquor. The characteristic pallor of the temporal half of the disc was noticed. The patient recovered after treatment by hypodermic injections of $1 / 3 \mathrm{gr}$. of strychnia every other day for four weeks.

DR. KFXSER said he believed that it was not always the amount of tobacco used that caused the defect, and that he would call attention to the case of a young man who called upon him in relation to failing vision, and on examination he could find nothing but suspicion of tobacco amblyopia. But upon questioning the patient said that he had been trying for a long time to smoke, but invariably nausea occurred on every attempt. $\mathrm{He}$ has tried weak and strong cigars with the same effect. He still persevered daily in the effort, thinking that was the only way to become a smoker. On desisting from any further attempt to use tobacco he recovered entirely. He did not drink any alcoholic liquor of any kind. This case shows that it is not the quantity of tobacco used that causes this disease, but as in this case, the tobacco may act as a peculiar irritant to the stomach - the brain subsequently becoming affected. In other words, there was in the case cited an idiosyncrasy against tobacco.

\section{SOME THOUGHTS ON THE ETIOLOGY, PATHOLOGY AND THERAPEUTICS OF PHTHISIS PULMONALIS.}

Delivered in the Section of Practice of Medicine, Materia Medica and Physiology, at the Fortieth Annual Meeting of the A merican Medical Association, June, 1889 .

BY W. L. SCHENCK, M.D., OF OSAGE CITY, KANSAS.

Every physician has measured swords with this Prince of Destroyers, and with-all it has too often proved the victor. In every age it has been carefully studied by the best minds in the profession, yet only the nostrum vender fully comprehends its methods and cure.

Truth is many-sided. Diversity in unity in the world of matter and of spirit is the thought of God. The mind of man, or the medium through which it acts, impels different investigators to follow different lines. Their eager search and earnest faith in their own methods may narrow their vision, but all is evolved that lies in the direction of their search. The impartial collaborator unifies their results, and truth is revealed.

It is generally agreed that phthisis is the consequent of a constitutional cachexy, which may be hereditary or acquired-not the disease, but the organic elements which, under certain conditions, are prone to the development of tubercleand that when the predisposition exists and the conditions are favorable, we have tuberculosis. All, however, do not agree upon its etiology and pathology. Until these are solved we cannot hope to find a rational treatment, preventive or curative. The predisposition or constitutional taint lies in the elements from which the tubercle arises. While there is some diversity of opinion as to the particular structure from which it springs, it is generally conceded that it originates in connective tissue. Fothergill says that "connective tissue is primitive tissue from which higher tissues are evolved." "Whether its cells, like the embryonic cell, are capable of evolving physiologically higher types of cells is, perhaps, doubtful, but under degrading influences they are prone to differentiate lower types of pathological cells. From this tissue, normally abundant throughout the body, and formed wherever through inflanmatory processes albuminous effusion occurs, springs nearly all the neoplasms.

I Handbook of Treatment, p. 192 . 
Tubercle is a neoplastic growth, and the tubercle cell is a pathological connective tissue cell, or possibly, as some distinguished pathologists assert, an infiltration of lymphoid cells in the aventitia of blood vessels, or small nodular masses of lymphoid cells around or within blood vessels or ducts. $^{2}$ But whether the tubercle arises from the connective tissue or from the lymphoid cell -the white blood corpuscles produced by the lymphatics-let us see, if we can, what constitutes the predisposition to its differentiation. Whenever connective tissue approaches an embryonic type, is rich in nuclei and young cells, an exhausted vitality, from whatever cause, leaves this immature plastic cell growth devitalized and prone to retrograde metamorphosis, and the new cells are, according to Virchow, "a pitiful production, from their very outset miserable." Like all the lower forms of life, they substitute rapidity of proliferation for perfection of development. Their rapid reproduction presses them one against another and they form a tubercle. The pressure strangulating the circulation at the centre, the central cells are devitalized and soon degenerate into a shrunken, cheesy mass, the cheesy transformation being often followed by purulence. While this is the common course, the result varies with the extent of degradation, and reaches its acme in the milliary tubercle, where, through their rapid proliferation, the cells are detached and carried through the lymphatic vessels to other locations. The more degraded the cell, the more dangerous the disease.

Where there is defective nutrition, or vital deterioration from any cause, in those who inherit or acquire a facile type of connective tissue cell, it is prone to differentiate the lower type of tubercle cell; but why this specific differentiation, is, perhaps, as inscrutable as the physiological differentiation from the embryonic cell of the various cells of the body. But the fact that embryonic cells do thus differentiate on and up to all the parts of the perfectly developed animal makes it less wonderful that some of their offspring, under given influences, should differentiate pathological cells, the pathological structures being only physiological diversions. While we may not know why special deteriorations occur, the influences that lead to them, their etiology is less obscure. We know that any cause sufficient to produce vital deterioration beyond a given point will cause the development of tubercle where the predisposition exists. The amount of deterioration is, however, by no means a fixed quantity, but varies with the predisposition. Yet the neoplastic growth never develops during robust health. Exhausting fevers, inflammatory processes, syphilis, excess of venery, pregnancy, lactation, corroding care, any cause that lowers vital action, especially when increased by unsani-

\footnotetext{
${ }^{2}$ H. F. Formad, paper before the Phil. Med. Soc., I 883 .
}

tary surroundings and climatic vicissitudes, tends to tubercle.

Catarrh, bronchitis and pneumonia have been considered causes of consumption, but it does not arise directly from inflammatory processes and it is doubtful whether any cause beyond innutrition and vital deterioration is necessary to its development. Without lowered vitality, general or local, there is no tuberculosis.

The contagiousness of phthisis is said to be sub judice. An epithelial cell may be transplanted, as in skin grafting, and on favorable soil, with favorable surroundings, will proliferate. So it is not impossible that a tubercle cell, that can be transplanted through the lymph or blood vessels may be transferred from lung to lung; but this we think is the extent of its contagiousness. Each individual cell possesses an individwal life, and where we find a cell there must have been a progenitor. It is as impossible for a cell to construct itself out of non-cellular matter as it is for an alga or an animalcule, a mastodon or a man, to build itself out of formative material. We know no life de novo.

From the time of Hippocrates there have been believers in the contagiousness of phthisis, and a large number of cases have been collected that seem to confirm the doctrine, but compared with those that have escaped contagion where the closest human relations have existed, they are far too few to establish any law, and a humane profession will not ostracise the unfortunate consumptive and deprive him of the sympathy and assistance of friends without further proof. The proof is too like that of the patent medicine man who hunts up the exceptional cases that get well and omits the hosts that die. Its contagion is certainly unlike that of variola, cholera and yellow fever, which do not occur independent of contact, and which do occur, in the unprotected, on contact. The history of such hospitals as the Brompton, London, and the Brehmers, Görbensdorf, as well as the observation of the million, show its contagiousness or portagiousness exceptional if not nil. Since the promulgation of the germ theory of disease, the theory of contagion has received a fresh impulse, not from any proof of contract through contact, but because of the bacilli found in dead tubercle cells, it being assumed that the bacilli are a contagium vivum. Animals and vegetables, microscopic or otherwise, have their habitat and their significance. Every specific degeneration has its dead tissue and doubtless its specific microbe. In the cell death incident to the tubercle, the bacillus tuberculosis finds its proper nutriment, and it may be the ferment that changes the caseated cell into putrid, semi-purulent matter.

We have before us the results of many experiments, by distinguished scientists, with microbe cultures. With all due respect for those by 
whom they were made, they have never created a tubercle cell or tuberculosis. By taking animals strongly predisposed to tubercular degeneration, placing them in unnatural confinement and on unusual diet, and injecting microbe cultures, it is alleged they have demonstrated the contagium of phthisis. With such animals and such surroundings, we may safely predicate phthisis after the injection of any ferment, or from substances, as pulverized glass, that are not ferments, or without any injection. A specific ferment must produce a specific disease and nothing else, and a specific disease must be caused by a specific ferment, and by nothing else.

When the animals have been inoculated with the "culture" and permitted their accustomed liberty the experiments have failed, and they have failed with the unnatural surroundings in animals in whom there is no strong tendency to the disease.

The argument for germ causation is: "It seems to be established that the so-called bacillus tuberculosis is uniformly present in tuberculous products and as uniformly absent in other products, that it is generally present in the sputa of phthisical patients and never present in the sputa of non-phthisical patients, and that tuberculous disease in animals may be produced by inoculation with the organism after cultivation has been sufficiently continued to eliminate all else pertaining to the tuberculous product. On these data are based the conclusion that phthisis is an infectious disease-in other words, that it involves in its causation a specific agent capable of self multiplication; that it is a communicable disease, and that the agent of communication is the bacilli tuberculosis; that is, this agent is contagium. The supposition that the bacillus is secondary to the tuberculous affection is not tenable, in view of the fact that the affection is produced by this organism after it has passed through several generations of culture out of the body." 3

Distinguished as is the authority from whom we quote, the bacillus is not universally present, and, as a rule, not present at the beginning of the disease, and it is not always absent in other products. It has not been proven that the introduction of this organism, either before or after culture, is uniformly followed by phthisis, or that the disease produced in the lower animals is identical with phthisis in man, as has been fully demonstrated by the experiments of Formad, Sternberg, Truesdale and others. To make this theory sustain itself, its advocates must not only explain away results and the absence of results, and similar results produced by pulverized glass, etc., but must go back to the theory of Læennec, that it is a special growth, unlike any other tissue; or of Carswell, that it is a secretion sui genp. 399 .

Austin Flint, M.D System of Medicine by Pepper, Vol iii, eris, disproved by the rational teachings of Virchow and Niemeyer. Certainly there is abundant proof that, as a rule, the dead cells precede the microbe, and the dead cells can arise from no other source than the tubercle cell. Virchow has truly said: "No form of morbid growth arises which cannot in its elements be traced back to some model which has previously maintained an independent existence in the economy."

The pathology of Virchow has been demonstrated, and that of Lænnec and Caswell disproved. Dr. Formad thinks Koch has taken a consequent for a cause. He says: "Koch has discovered that tubercle tissue is infested with bacilli, and this is correct; but this tubercle tissue is not created on account of or caused by the bacilli. These organisms invade the tissue wholly because it is a culture medium favoring their development." Prior to the cell death bacilli are not found in tubercle more than in the lung tissue before its differentiation.

The advocates of the germ theory tell us "our bodies outside, and especially inside, are covered by or contain billions of bacteria. All these microbes may become injurious under certain conditions. . . . With certain kinds of bacteria the animal cells carry on a constant 'fight for life,' while others, more deadly, destroy cellular elements at an early date, in spite of resistance;" and that "all the competent men the world over, who have searched and studied the subject experimentally, have come to an almost unanimous conclusion - and they form a colossal array of intellect-in support of the much praised and much abused germ theory." " Truth is not demonstrated and science not established by a "colossal array of intellect." Only a few years have elapsed since all the world believed "the Lord made the heaven and earth, the sea and all that in them is, in six days," In the formation of tubercle, "cellular elements" are not destroyed in their "fight for life" with the more deadly bacteria, "in spite of resistance," but are merely degraded to a lower type, and that regardless of the presence or absence of microbes. Nor is the theory as stated by Dr. Phillips in a paper read before the last International Congress any more tenable: "Phthisis is the consequent of the bacilli tuberculosis, whose fatal consequences are in all probability attributable to a power possessed by them in elaborating new products, which are afterwards absorbed." The premises granted, the probabilities may be as you like.

The investigations and conclusions of Pasteur and Kohn and Koch created great expectations in the treatment of disease, and especially phthisis, the opprobrium medicini, and many members of the profession made earnest search for specifics. They administered their agents with intent to destroy the pathogenic germ. In the treatment of

4 Paul Paguin, Kansas City Medical Record, July, 1888. 
phthisis they loaded their syringes with germicides and emptied them in the cellular tissue, the circulation, the lung, the tubercle, and finally into the rectum, hoping, it would seem, to steal a march on the enemy by the postern gate. The last treatment, instituted by Bergeon, which "went up like a rocket and came down like a stick," illustrates how prone we are, in the solu. tion of vexed questions, to jump at conclusions and adopt means wholly inadequate to the end, In the first volume of the JOURNAL OF THE AMERICAN MEDiCAi, Association for I 887 we find four articles and several editorials commending the "treatment," and one, by Dr. Lynch, of Baltimore, condemning it, and he was severely criticized by the learned and practical editor of THE JournaL, who said: "It was with some surprise that many members of the Association heard the Chairman of the Section on Practice of Medicine, in his address last week, utterly condemn the Bergeon treatment. .... The method seems deserving the most thorough and extended investigation." 5 The hopes entertained when the germ theory of disease was enunciated are amply illustrated in this treatment.

The ardent search for specific germicides has called forth this query from one of the greatest of living physicians, Dr. B. W. Richardson: "What have we done to be visited in the heavens above, in the earth beneath, and in the waters under the earth, with this pestis bacilorum, which is now regnant?"

If germs created tubercle and we could administer germicides of sufficient strength to destroy them without first destroying the patient, would not the tubercle remain and the question be cui bono? An account of the remedial measures employed for the cure of phthisis would fill volumes. Since Koch's discovery of the tubercle bacillus they have generally been leveled at the germ, and even in the recent treatment of phthisis by the inhalation of hot air, which promises well, many seek its rationale in the destruction or hindered development of germs. As well say that we crush germs in the movement cure, as that we scald them in the hot air treatment. Dr. Wm. Porter, of St. Louis, has well said: "No practical gain has been made based upon the hypothesis that the microbe is the factor per se. So far as our present knowledge extends, the bacillus is to phthisis as smoke to fire: it may indicate its existence, yet neither incites nor intensifies the combustion." "

Phthisis being a disease of hereditary or acquired tissue degeneration, its rational treatment must lie in tissue restoration, in the use of such measures as will arrest retrograde action and, if possible, restore the degraded cells to their normal condition. Dr. Joseph Jones, of New Or-

Journal of the American Medical Association, June 18 , I887.

Gedical Bulletin, Philadelphia, March, I 888 . leans, La., says the remedies of the greatest use appear to be cod liver oil, phosphates and hypophosphites of iron, zinc, sodium, potassium, strychnine and the bitter tonics.' For a clear statement of a rational treatment we may well refer to "Fothergill's Handbook of Treatment," pp. 199-212, and fully endorse it: "Every case has its own peculiarities and its own exigencies, and must be studied in detail." No routineism, whether with germicidal intent or otherw ise, can lead to victory.

If the importance of an easily digested oil in the treatment of phthisis, preventive and curative, required emphasis, we need only refer to the "blubber'-eating people of Greenland, Lapland and Iceland, where consumption is never indigenous, and where, when imported, seldom extends to the second generation." Yet in these countries all the conditions that tend to the disease are present - a low altitude, a damp atmosphere, and a most inhospitable climate; homes, if not built beneath the earth, usually built of earth, innocent of ventilation and cleanliness, with their occupants packed together like sardines, that they may maintain the greatest possible bodily warmth.

The absence of fat tends to tuberculosis. Its presence tends to arrest and restore tuberculous degenerations. How, we may not know but, in some way it facilitates metamorphosis, aiding both in the removal of effete matter and in building up degraded tissues. Thus we find tubercle developed in cattle and sheep by starvation through the winter in process of repair after the summer's fattening. Chambers, in his admirable little volume on "The Indigestions," says of oil: "It is itself the material by which life is manifested. Under its use beneficial influences are exerted throughout the whole body. Old wounds and sores heal; the harsh, wrinkled skin regains. the beauty of youth; debilitating discharges cease, at the same time the normal secretions are more copious; the mucous membranes become clean and moist, and are no longer loaded with sticky epithelium; the pulse becomes firmer and slower, that is to say, more powerful, for abnormal quickness is alwavs a proof of deficient vitality. Such are the effects, perfectly consistent with physiology, of supplying a sufficiency of molecular base for interstitial growth. To find the easiest assimilated oil, and to prepare the digestion for the absorption of oil, are the main problems in the cure of consumption."

As an important corollary to this we should insist upon the cultivation of a taste for fat, especially in children of a consumptive heredity. Alcohol has been commended as the hydro carbon in the treatment of phthisis, the argument being.

Journal of the American Medical Association, March, $18 \times 6$ 8 "Consumption as a Contagious Disease," by Dr. Rumbold. Isso. "The Homes of the Edas," by Warreford S. Low, 1879. 
that "experiment has shown that the combustion of one grain of alcohol raises the temperature of water $\mathrm{I}^{\circ}$ centigrade. Cod liver oil in the same quantity brings to a like degree of temperature seven litres of water. Hence, the relative heatproducing powers of alcohol and the well-known nutrient oil are as three to four." In the prevention and cure of phthisis oil does more than produce heat, and if it was otherwise, physiological chemistry does not prove the body an alcohol lamp. In all the alcohols and ethers hydrogen is greatly in excess of oxygen. In ethytic alcohol we have $\mathrm{C}_{2} \mathrm{H}_{i 1} \mathrm{O}$. Such compounds demand oxygen at any cost. When introduced into the body, either by inhalation or imbibition, instead of oxydizing, they deoxydize the blood and tissues; instead of increasing, they decrease metamorphosis and the generation of heat; instead of generating nervous force, they produce anæsthesia. The demand of the body for an oxydized blood increases the frequency of the heart's action, but through want of energy from want of oxygen the rapidity of debility is substituted for force. Vital metamorphosis is diminished and vital heat decreased. In all treatment we must strive to improve digestion and assimilation, and we can not renew tissue without the removal of that which has become useless. Alcohol "pickles" the tissues; oil aids in their removal and renewal.

Prof. Jaccoud, than whom we have no better authority, in his work on "The Curability and Therapeutics of Phthisis," considers the disease curable in all its stages-not all cases, but curable as are other diseases. In all treatment he relies largely upon the influence of climate, adapting its conditions to the individual case. Notwithstanding Jaccoud's dictum, there are widely differing opinions as to which is the best climate; thus, we find the balmy air of sea-surrounded Orotava praised, the soft warm breezes of St. A ugustine, Fla., the fragrant odors and almost tropical warmth of the Louisiana pine-belt, the high cold climate of Colorado, and the damp and chilly atmosphere of lake-girt Michigan. ${ }^{10}$ As these widely differing opinions seem but the varied notes of "Home, Sweet Home," we must consider principles and statistics.

Before we can give intelligent advice to invalids we must understand the various elements entering into and producing what we call climate, and their impress upon life, as thoroughly as the etiology and pathology of disease. Webster defines climate as "the condition of a place in relation to the various meteoroiogical conditions, as temperature, moisture, etc."

Climates are mainly created and infuenced by latitude, topography, superficial strata and the presence or absence of large bodies of water, and are the aggregate of atmospheric conditions of particular localities at specified seasons. The

\footnotetext{
Iransactions International Medicai Congress. Vol, v.
}

chief elements to be considered in climatic treatment are: I, purity ; 2, rarefaction, as produced by altitude; 3 . dryness; 4 , temperature ; 5 , variability ; 6 , sunlight ; 7 , electricity ; 8 , atmospheric motion. The first and second elements are chiefly infiuenced by altitude, the others by latitude, configuration, and porosity of the surface and relation to bodies of water.

Dr. Dennison advocates the "dry, cool, rarefied, stimulating and sunny atmosphere of Colorado" because, among other reasons, "cold stimulates and heat depresses." Is not this as fallacious as the Thompsonian dogma, "heat is life, and cold is death?" A limb mutilated beyond hope of recovery is restored through the stimulus of hot water dressings, and a frightful post-partem hæmorrhage is arrested by the stimulus of hot intrauterine injections. "In media tutissimus ibis" must be one rule in selecting temperature for the consumptive. An atmosphere that stimulates through altitude, and yet woes to out-door life, is most favorable for the prevention and cure of phthisis. It is not the heat or the cold that tends to cure in phthisis. Robust health may endure an inhospitable climate, but such a climate does not produce robust health in those of marked tuberculous heredity; while in damp air, cold or warm, containing less oxygen than dry air, which is absorbed less readily from the moist membrane, there is diminished oxydation of the blood engorgement of central organs. Dr. D. thinks nightly chilling and sometimes freezing renders the atmosphere "inimical to germ life." We don't know so much about the health of the germ, but we know such conditions are inimical to human health.

Whether from the direct effect of abstraction of moisture from the pulmonary tissue, or the con. sequent control of pulmonary temperature, or other cause, a dry atmosphere is essential to climatic treatment. Change in temperature, when the range is not too wide, may not injure vigorous life; but the alternations of temperature, the hot days and cold nights, so common in all damp climates, leads to engorgement of central organs - spleen, liver, kidneys, lungs, - to periodic and congestive fevers, to lowered vitality and to consumption, wherever the predisposition exists. Damp, hot days and damp, cold nights produce directly opposite results to dry, high altitudes, where external tissues are hyperæmic and internal organs anæmic. Cold condenses the atmos phere. In cold weather, at low altitudes, the full use of the pulmonary tissue and circulation is not required, and there is tendency to atony and the tubercle cell. In simply cold climates, of whatever altitude, sudden and extreme changes fall heavily upon the exposed lungs, and such changes cannot be avoided. Much of the time must necessarily be spent in artificially heated rooms, too of ten illy ventilated, 
between which and the ont-door air there is a difference of many degrees. It goes for the saying that the advantage of climate is the climate, and not the heated air of the living-room. A climate that permits and invites out-door life is a necessity to satisfactory climatic treatment. Cold and rain confine the patient in-doors; a warm, moist air tempts to indolence, and a hot, dry air leads to idleness and the shade, while a high, dry air of vernal temperature stimulates to out-door life and exercise, and so fills all the conditions of climatic treatment.

Climatic treatment is based upon more rational grounds than the destruction of germs. In an atmosphere rarefied by altitude the pressure upon the surface of the body is diminished and the vessels of the periphery are turgescent, while the viscera are comparatively anæmic. The pulmonary circulation freed from hyperæmia, congestion and obstruction, tendency to hæmorrhage is prevented or relieved, respiration is full and free, the cerebro-spinal functions are more active, the great central glands relieved of remora and congestion, effete matter is more thoroughly removed, the appetite, digestion and nutrition are improved, the desire and capacity for exercise increased, and $w$ e begin to feel

\begin{abstract}
"The wheels are just as strong as the thills, And the floor just as strong as the sills,

And the panels just as strong as the floor,

And the whippletree neither less nor more,

And the back crossbar as strong as the fore,

And the spring and axle and hub encore."
\end{abstract}

The "hardy mountaineer," with his physical and mental activity, does not owe all his growth to mountain scenery, but illustrates the beneficial effects of altitude. The rarefied atmosphere and the relative anæmia of the lungs, other things being equal, demands and permits full draughts of air, while the brain and all the great vital organs, permitting an unobstructed circulation of the vital current, tissue degradation and deterioration are prevented or relieved.

Prof. Jaccoud says: "Mountainous clinates at the height of from 4,900 to 6,200 feet have in reality a double effect: Firstly, a general one, by which the constitution is restored to a healthy condition; secondly, a local one, by which the activity of respiration is increased to a maximum, while the lung is protected from the effect of congestion and hyperæmia. Climates which, on account of their more northern latitude, present analogous conditions of temperature at a lower altitude, produce the same tonic effect. They have not, however, the same mechanical influence upon the lungs, this being entirely due to barometric pressure. Climates with moderate pressure are wanting in the mechanical action of rarefied atmosphere, and there is insufficient tonic and fortifying effect; nor do they possess that special purifying effect peculiar to high altitudes; they therefore fulfil only secondary indications-secondary in themselves, or at the time when they occur. While such climates have no curative effects on the disease and are not preventive of fresh tubercle, they may, on account of having a temperate, or warm, fresh temperature in winter. act favorably upon any preëxisting bronchitis or pulmonary catarrh. Confinement within doors is unnecessary, and much of the time may be spent in the open air without danger of provoking bronchitis or pneumonia, which would not be the case in a more rigorous climate, or one having greater variability of temperature. It is thus seen that climates of the second class, while of an undoubted value in the treatment of phthisis, are only of secondary importance."

Altitude in any latitude that does not permit to the consumptive out-door life loses much of its advantage. If we can find a locality with a comparatively dry atmosphere which at $4,000,6,000$, 8,000 or 10,000 feet will permit patients to live largely out-of-doors, they will at the same time get the benefit of barometric pressure, climate and healthful exercise. Though not a resident of New Mexico, its barometric pressure will range from 4,000 to I0,000 feet, with a climate that will permit and stimulate out-door exercise, with which its hygrometric conditions will rarely interfere.

The damp, cold climate of lake-encircled Michigan is excellent for consumption, but bad for the consumptive, and its statistics prove what science teaches. According to the census reports of 1870 and 1880 , it has a higher death-rate from phthisis than any other inland State in the Union. Of its deaths in 1870 , I6.4 were from phthisis, and in $1880,13.2$.

In the States lying upon and near either ocean in the northern portion of the United States, notwithstanding their altitude, we have the highest death-rate from phthisis, the acme being reached in Maine, where, in $1870,25.6$ of the deaths were from consumption, and in $1880,19.2$; in New Hampshire they were 22.2 in 1870 , and 15.7 in 1880 ; in Massachusetts, 19.9 and 15.7 ; in Connecticut, 17.9 and 19.2 ; in Rhode Island, 20.1 and 14.7 ; in California, I 3.8 and 15.6 ; in Oregon, I8.2 and $12 . \mathrm{I}$.

The warm, damp air of the Gulf States, with their lower altitude and higher temperature, give much more favorable statistics than those somewhat similarly situated as to moisture, but with more rigorous climates. Thus, the percentage of deaths from phthisis, as shown by the census of 1870 and 1880 , were 5.7 and 8.0 in Georgia ; 6.4 and 8.0 in Alabama; 7.0 and 9.0 in Mississippi : 7.0 and 8.2 in Florida, and 7.7 and 8.2 in Louisiana.

Colorado and Nebraska, so highly lauded for the influence of their climate on the consumptive, show by the same census a slightly larger pro- 
portion of deaths from phthisis than the lowlying but warm States on the Gulf of Mexico. Thus, in Colorado 8.5 and 8.2 were from phthisis, and in Nebraska, 8.7 and 7.0. In New Mexico the deaths from phthisis are given in 1870 as 3.8 , and in $1880,2.5$, and in Arizona, 4.0 and 6:9, and this where the native population suffer largely from a specific disease that tends to a type of phthisis.

From the view we have taken of the etiology and pathology of phthisis, as well as from statistics, we conclude that a sanitarium for consumptives in New Mexico, away from the hot springs, with their excess of moisture, upon an arroyo of 4,000 or 5,000 feet above the sea, with cottages extending up the mesa to 10,000 feet, permitting patients to be moved up or down, as their condition permits or requires, will secure to the consumptive all possible climatic advantages and make for them the most perfect retreat known to any country or clime.

Yet we must remember that in all climatic treatment we must "temper the wind to the shorn lamb." In the flat and narrow chest, in tuberculous deposit confined to the apex, or yet more extensive if the purulent stage has not been reached, altitude, high, dry and equable, with a climate that encourages out-door life, is positively preventive and curative, not in a day or a year, but continued until the cure is complete. When caseation and softening are more extended, a mild, dry and pure atmosphere is required, stich as may be found in the lower altitudes of New Mexico and in the Carolinas, Tennessee and Georgia. When the tuberculous deposit is extensive, expectoration copious, hectic marked and emaciation extreme, the probabilities of cure are so small that the pleasures of home, where love may make the dying bed "soft as downy pillows are," should not be exchanged for an arduous journey to end in a final struggle away from the comforts and consolations of home and friends.

\section{DISPOSAL OF HOUSE-REFUSE.}

Rcal in the Section of Statc Medicine at the Fortieth Annual Mcrting of the American Mcdical Association. June, 1880. BY AIFRED LUDLOW CARROLL, M.D., OF NEW YORK.

Household life necessitates the deportation of several different kinds of refuse matter, consisting of excremental substances, liquid wastes from the kitchen and the laundry, baths and basins, garbage, sweepings and dust of various sorts. As regards the first of these, the average for each individual is 57 pounds of frecal excreta and II 4 gallons of urine annually; or, for a family of five persons, 285 pounds and 570 gallons respectively. The danger from these is not when they are freshly voided, but after decomposition has set in, favoring the evolution of noxious gases and vola- tile products of putrefaction. Where atmospheric oxygen has free access, the principal results of decomposition are ammonia, carbonic acid and water; but in large accumulations, where air can not thoroughly penetrate, deleterious compounds are generated, bacterial ferments multiply, and ptomainal products are given off in increased quantity. An additional peril arises where the intestinal discharges are impregnated with the virus of specific diseases, such as cholera, enteric fever, and probably other diarrhoeal maladies, though even in this case it seems to be requisite for the development of the contagium that decomposition shall have reached a certain stage. When urine is mixed with fæces, fermentation occurs more rapidly and with greater evolution of volatilized organic products. For these reasons it is of prime importance that such matters be removed from any possibility of communication with the interior of the house, or of its inmates, before they shall have time to decompose; that is to say, for practical purposes, within twelve hours.

But a grievous mistake, made by many engineers and by some superficial writers on hygiene, is to consider the intestinal and renal dejecta as the only things to be cared for, whereas in reality they constitute less than one per cent. of the offensive residua which should be speedily removed from inhabited places. The feathery masses of decaying epithelium from basins and baths, or the organic scourings from soiled clothing, not only afford fertile culture media for microzymes, but are often specifically infected; the culinary outpourings are virtually weak organic broths, responding readily to inoculation; indeed, all the water supplied to the domicile is discharged in so fouled a condition that prudence forbids its retention on or about the premises. There is little difference in the sewage of towns whether excremental matter be admitted or excluded, and in populous cominunities where "dry methods" are used it is found necessary to construct sewers in addition. Liernur's pneumatic system and other schemes based upon the single view of the manurial utiiity of undiluted excreta are open to the same objection.

If the arch-enemy of mankind had been asked to suggest the most mischievous method of dealing with these waste products, he could not have devised a more diabolical one than that which is commonly adopted, not alone in sequestered rural regions, but in the majority of villages, and which lingers as a relic of barbarism even in many cities, to wit: the storage of them in pervious privy-pits and cess-pools, whence the festering liquefied filth permeates the soil over a wide area, polluting the surface wells which are usually in convenient proximity, and poisoning with its noxious exhalations the ground atmosphere which is drawn into the basements of ill-constructed houses. 